\title{
LICÕES EM ENGENHARIA SOCIAL: A LÓGICA DA MATRIZ DE PROJETO NA COOPERACÃO INTERNACIONAL
}

\author{
Catarina Morawska Vianna \\ Universidade Federal de São Carlos - Brasil
}

Resumo: Este artigo explora os princípios da engenharia social que embasam o trabalho das agências internacionais de desenvolvimento. A partir de um relato etnográfico de um treinamento na Catholic Agency for Overseas Development, a agência católica de desenvolvimento internacional da Inglaterra e País de Gales, será apresentado o pensamento lógico da matriz de projeto a partir do qual os técnicos da organização são incitados a operar. Argumenta-se que o fracasso crônico dos projetos, em geral atribuído à pouca familiaridade dos parceiros com as ferramentas de aplicação do pensamento lógico à solução de problemas sociais, decorre da temporalidade subjacente aos projetos, que supõem o vácuo social e a sucessão de eventos tal como previsto no papel. Isso nunca ocorre, já que nas organizações parceiras que trabalham diretamente com os beneficiários as contingências do dia a dia criam um descompasso entre a composição fixa vislumbrada no projeto e as composições efêmeras que emergem durante a sua implementação.

Palavras-chave: agências internacionais, cooperação internacional, engenharia social, projetos.

Abstract: This paper explores the principles of social engineering that underpin the work of international development agencies. By presenting an ethnographic account of a training at the London headquarters of the Catholic Agency for Overseas Development, I will explore the logical thinking expected from programme officers when designing log-frames for projects. I argue that the chronic failure of projects, generally attributed to the unfamiliarity of partners with the tools that apply logical thinking to the solution of social problems, derives in fact from the temporality that underlie projects. They suppose a social vaccum and a sequence of events that never takes place as laid down on paper, since contingencies of everyday life experienced by partner organizations who work directly with beneficiaries create a mismatch between the fixed composition envisioned in the project and the ephemeral compositions that emerge during its implementation.

Keywords: development, international agencies, projects, social engineering. 
Em 2007 a Catholic Agency for Overseas Development (CAFOD), agência católica de desenvolvimento internacional ligada à Conferência Nacional dos Bispos da Inglaterra e País de Gales, inaugurava o seu novo sistema de gerenciamento de projetos e programas, o Programme Cycle Management System (PCM) [Sistema de gerenciamento de ciclo de programa]. ${ }^{1} \mathrm{O}$ sistema PCM era visto como central ao trabalho internacional da CAFOD, já que operacionalizava a chamada abordagem programática prevista na política mais geral da organização para o período 2005-2010, anunciada no documento CAFOD 2010: building communities for change [Construindo comunidades para mudança] (CAFOD, 2005). Esperava-se que a nova abordagem contribuísse para o aumento do impacto dos seus programas internacionais por meio da diminuição do número de projetos mantidos através de parcerias isoladas e do estabelecimento de apenas dois ou três programas mais amplos por país. ${ }^{2}$ As equipes de programa da CAFOD, portanto, estavam em meio a uma grande revisão de todas as suas parcerias, que deveriam ser mantidas apenas na medida em que se enquadrassem na nova agenda temática da organização e nos programas estabelecidos em cada país. Estavam às voltas também com uma série de treinamentos que as familiarizavam com os novos procedimentos para gerenciar os projetos e programas e, no limite, relacionar-se com parceiros.

Este artigo se propõe a realizar uma descrição etnográfica de um dos treinamentos que a CAFOD oferecia a seus funcionários a respeito dos quatro estágios do novo ciclo PCM - 1) análise; 2) desenho; 3) ação; 4) impacto -, sobretudo no que concerne à elaboração de documentos. Pretende-se com isso contribuir para as discussões recentes na área da antropologia da cooperação internacional no Brasil ao enfatizar um dos aspectos centrais da vida dos atores envolvidos no mundo da cooperação internacional, qual seja, a mobilização de saberes técnicos.

\footnotetext{
1 Este artigo é uma versão modificada de um dos capítulos de tese de doutorado defendida no Programa de Pós-Graduação em Antropologia Social da Universidade de São Paulo (Morawska Vianna, 2010). Tratase de uma etnografia baseada no deslocamento institucional pela Rede Tarrafa: 22 semanas de trabalho de campo em três grupos populares que atuam junto a crianças e adolescentes de seus bairros em Recife e Olinda; e 53 semanas na sua financiadora CAFOD em Londres (no escritório da equipe responsável pelos projetos no Brasil dentro da seção da América Latina na sede da CAFOD, e no escritório regional da CAFOD localizado na diocese de Westminster). Optou-se por manter expressões em língua inglesa no corpo do texto por se tratar de conceitos correntes entre meus interlocutores de campo. Todas as traduções são minhas.

2 Cf. CAFOD (2005, p. 6-7).
}

Horizontes Antropológicos, Porto Alegre, ano 20, n. 41, p. 87-115, jan./jun. 2014 
Etnografias de projetos de desenvolvimento ou de agências de cooperação internacional são relativamente recentes na antropologia brasileira. O trabalho pioneiro é a etnografia de Gustavo Lins Ribeiro (1994) sobre a construção da hidrelétrica de Yacyretá, na Argentina. Ainda que o autor recentemente venha propondo esquemas analíticos amplos a respeito do que denomina "campo do desenvolvimento" (ver, por exemplo, Ribeiro, 2008), seu primeiro trabalho é eminentemente etnográfico, com a descrição dos grupos de interesse envolvidos no projeto de Yacyretá, como grupos locais, agências governamentais e consultores. ${ }^{3}$

À parte desse trabalho, a literatura mais específica em torno de agências de cooperação internacional é bem mais recente, e vem explorando temas tão diversos quanto o papel da cooperação internacional para a formação do Estado timorense (Silva, 2008; Silva; Simião, 2007); o discurso imagético da cooperação para o desenvolvimento da União Europeia (Nicaise, 2007); o processo de formação e desenvolvimento dos programas da cooperação norueguesa junto aos povos indígenas (Barroso Hoffman, 2009); as políticas para a juventude promovidas pela Organização das Nações Unidas para a Educação, a Ciência e a Cultura (Unesco) no Brasil na década de 1990 (Castro, 2009); a atuação da Agência de Cooperação Alemã (GTZ) no Brasil (Valente, 2010).

Vale apontar que o uso do termo "cooperação internacional" como definidor dessa área de pesquisa denuncia a maior frequência de estudos sobre relações que envolvem o Estado. Há, contudo, trabalhos que focam as relações entre organizações não governamentais internacionais e organizações locais, não referidas pelos atores como de cooperação, mas parcerias. Exemplos encontram-se em Rickli (2010), com sua etnografia sobre a atuação das organizações protestantes holandesas KiA (Kerk in Actie) e Aliança ICCO em projetos no Brasil; e em Morawska Vianna (2010), com trabalho sobre a parceria entre a já mencionada organização católica CAFOD e organizações populares em Recife e Olinda.

Ainda que nesses estudos haja menções a metodologias de planejamento e gerenciamento de projetos, como ocorre em Valente (2010, p. 43-48) ao

\footnotetext{
Para menção de como o trabalho de Ribeiro se situa em relação a outras etnografias de grandes projetos de desenvolvimento, ver Herzfeld (2001, p. 152-170). Esforços na antropologia brasileira de sintetizar o debate da antropologia do desenvolvimento fora do país encontram-se em Schröder (1997) e Schröder e Naase (2004).
} 
discutir a GTZ, muito pouca atenção é conferida à elaboração dos documentos em si, em especial à mobilização de saberes técnicos e aos efeitos que estes operam. Análises desse tipo têm sido cada vez mais frequentes, como é o caso de algumas coletâneas (Ong; Collier, 2005; Riles, 2006; Strathern, 2000). Ademais, discussões recentes apontam para a importância da dimensão estética dos documentos em análises de relações institucionais (Hull, 2012; Riles, 2001, p. 70-91, 2006). Merece destaque o artigo de Harper (2000) sobre as missões do Fundo Monetário Internacional (FMI). O autor descreve o processo de criação do quadro geral de uma "economia nacional” a partir da mobilização de saberes aritméticos e econométricos em reuniões com representantes de governos, e do cruzamento dos dados ali produzidos com dados coletados por técnicos do FMI em outras instâncias. Com isso, confeccionam-se documentos que justificam as decisões da organização em relação aos Estados com quem estabelece acordos.

Argumenta-se aqui que atentar para a elaboração dos documentos na cooperação internacional permite perceber os princípios da engenharia social que marcam o trabalho de agências internacionais, em especial a elaboração de composições do social das quais depende a execução de seus projetos. ${ }^{4}$ Permite também perceber como as organizações mantêm as suas agendas atreladas às agendas de organizações financiadoras. Em outras palavras: a formulação dos documentos em cada um desses estágios alinha o trabalho de cada equipe dentro da CAFOD à agenda temática da organização como um todo e, mais amplamente, à agenda dos financiadores da CAFOD.

Isso fica claro ao se analisar a forma como os documentos ligados a projetos e programas da CAFOD refletem o estabelecido em outros documentos formulados em níveis hierárquicos superiores ou em outras organizações financiadoras. Em um primeiro nível, o Programme concept note (PCN) [Nota de conceito de programa], formulado no primeiro estágio do PCM, deve estar alinhado ao Country strategy paper (CSP) [Documento de estratégia para o país], elaborado a cada cinco anos pelo gerente de programa. Em um segundo nível, o CSP deve seguir as diretivas estabelecidas pela política geral da organização em vigor, o CAFOD 2010. Se o CAFOD 2010 estabelecia como setores

4 Composições do social são aquilo que os atores vislumbram como o seu campo de intervenção, definido por elementos (pessoas, coisas, categorias, nomes) postos em relação dentro de fronteiras de mundo delineadas ciclicamente, a cada novo estágio do sistema PCM (cf. Morawska Vianna, 2010).

Horizontes Antropológicos, Porto Alegre, ano 20, n. 41, p. 87-115, jan./jun. 2014 
prioritários economic advocacy [advocacia econômica], sustainable livelihoo$d s$ [modos de subsistência sustentáveis], conflict resolution and peace building [resolução de conflitos e construção da paz] e HIV/Aids (CAFOD, 2005, p. 6), dificilmente seria possível estabelecer como programa para um país algo que fugisse de um desses temas. Da mesma forma, em um terceiro nível, a política geral da CAFOD procura estar em consonância com a de doadores institucionais, como é o caso daquelas instituídas pelos DFID white papers [diretrizes de políticas da agência britânica de desenvolvimento internacional]. Estimulase entre os funcionários que gerenciam projetos e programas a ligação entre os documentos PCN, CSP, CAFOD 2010 e DFID white papers.

Se um olho do engenheiro social recai sobre o mundo dos beneficiários, o outro estará posto sobre a trilha de documentos (matriz de projetos, PCNs, CSPs, políticas organizacionais) elaborados em diferentes organizações. É do esforço incessante do alinhamento de seus documentos às políticas, prioridades estratégicas e ferramentas de trabalho de outras agências que as equipes da CAFOD criam as condições para que a organização seja vista como possível parceira por grandes financiadores, desde órgãos estatais em países em desenvolvimento, órgãos do governo britânico, organismos multilaterais, instituições privadas de financiamento.

A abordagem programática, portanto, era parte da estratégia da CAFOD para aumentar ao máximo as suas conexões institucionais com agências financiadoras que pudessem atuar como cofinanciadoras de seus projetos. Na posição de corresponsável pelos programas, a CAFOD devia garantir que a sua execução e a mensuração de seu impacto estivessem de acordo com um certo padrão de prestação de contas exigido pelas cofinanciadoras. Isso demandava ou que as parcerias fossem seladas com organizações que facilmente mobilizavam saberes técnico-burocráticos (em especial referentes ao planejamento e à prestação de contas), ou que estas fossem capacitadas para tanto. Daí se compreende outra iniciativa estabelecida no CAFOD 2010 como prioritária: a capacity building [capacitação] dos parceiros-chave. Na abordagem programática não havia mais espaço para o apoio a grupos informais. Como Joseph, funcionário que costumava trabalhar na extinta seção da Europa do Leste na CAFOD, disse: "Quanto mais programação, mais a conexão com a base se perderá."

Esse era o caso de um dos parceiros da CAFOD em Recife e Olinda, o Projeto Tarrafa, três organizações de base que trabalhavam com crianças e adolescentes de seus próprios bairros desde a década de 1980 e que desde o 
início das atividades contavam com o apoio da CAFOD. Com a nova abordagem programática, todos os que faziam parte da Tarrafa deveriam ser capacitados, desde os funcionários da CAFOD até os educadores e coordenadores dos grupos em Recife e Olinda. O presente artigo trata dessa "capacitação": o dar a ver um modelo consoante o qual os atores devem operar e saberes que devem mobilizar.

A partir de um relato etnográfico de um treinamento para funcionários da CAFOD, será apresentado o pensamento lógico da matriz de projeto a partir do qual os técnicos em sua sede em Londres desenvolvem composições do social que têm como intuito "atacar a sociedade" e superar a pobreza. A partir dessa perspectiva, o insucesso dos projetos é em geral atribuído à pouca familiaridade dos parceiros com as ferramentas de aplicação do pensamento lógico à solução de problemas sociais. Argumenta-se, no entanto, que esse fracasso crônico decorre da temporalidade subjacente aos projetos, que supõem o vácuo social e a sucessão de eventos tal como previsto no papel. Assim, para serem considerados bem-sucedidos, os projetos devem se dar da forma mais similar possível a si mesmos. Isso nunca ocorre, já que nas organizações parceiras que trabalham diretamente com os beneficiários as contingências do dia a dia criam um descompasso entre a composição fixa vislumbrada no projeto e as composições efêmeras que emergem durante a sua implementação.

\section{Sistema de gestão de ciclo de programa (PCM)}

Como a implementação do PCM era prioridade para a divisão internacional, uma equipe havia sido contratada para desenhar e implementar o novo sistema. Ela era também responsável por auxiliar os funcionários de programas a avaliar, monitorar e rever o apoio da CAFOD a projetos e programas. Para isso, oferecia diversos treinamentos, como o PCM refresher and update training [treinamento de atualização do PCM], considerado altamente recomendável para as equipes da divisão internacional que lidavam diretamente com projetos e parceiros. ${ }^{5}$

Os responsáveis pela oficina eram os três funcionários da equipe do PCM: Philip, PCM project manager [gerente do projeto PCM], um homem em seus

5 Esta seção é em grande parte baseada no treinamento realizado em 15 de outubro de 2007.

Horizontes Antropológicos, Porto Alegre, ano 20, n. 41, p. 87-115, jan./jun. 2014 
40 anos vindo do setor privado; Gilbert, PCM development officer [funcionário de desenvolvimento do PCM], um jovem em seus 30 anos; e Bart, PCM advisor [consultor do PCM], um holandês também em seus 40 anos, com larga experiência como facilitador na aplicação de ferramentas de diagnóstico social utilizadas no trabalho de agências de desenvolvimento, como PEST(LER) analysis, stakeholder analysis, power analysis, problem tree, risk analysis, ${ }^{6}$ ferramentas que um bom engenheiro social deveria dominar.

A parte facilitada por Bart, que ocupava metade das $5 \mathrm{~h} 30$ de atividades, tinha como intuito estimular a produção de documentos de aprovação de projetos e programas com qualidade supostamente melhor. Bart iniciou o treinamento com a afirmação: "Queremos mais clareza nos resultados/efeitos e indicadores." " Todo o ciclo do PCM revolvia em torno do conceito de outcome, o que ficava claro logo no parágrafo inicial do manual do PCM:

CAFOD quer que seu trabalho com parceiros, projetos e programas resulte em mudanças nas vidas das pessoas. Queremos conferir mais ênfase nos outcomes dos projetos e programas que apoiamos. Para tanto redesenhamos nossos processos de Gestão de Ciclo de Programa (PCM). (CAFOD, 2007, p. 1, grifo no original).

Não tão imediatamente era visível o porquê da maior ênfase nos outcomes dos projetos e programas. Apenas na metade do treinamento, Bart declara "CAFOD não inventou isso" -, e logo a seguir menciona como outcome era usado pela Big Lottery, uma agência financiadora de projetos ligada à loteria no Reino Unido, a quem a CAFOD eventualmente solicita recursos. Perguntei-lhe: quem trabalha com objective e quem trabalha com outcomes? Big Lottery trabalha com outcome; USAID [agência estadunidense para o desenvolvimento] com

6 PEST(LER) analysis é uma análise de situação ou contexto que leva em conta fatores (P)olíticos, (E) conômicos, (S)ociais, (T)ecnológicos, (L)egais, ambi(E)ntais, (R)eligiosos. Stakeholder analysis é um processo que identifica pessoas ou grupos com interesse num projeto ou programa. Power analysis é a análise das relações de poder entre grupos de pessoas ou indivíduos. Problem tree, ou árvore de problema, é uma ferramenta para explicitar causas de problemas específicos. Risk analysis, ou análise de risco, é um processo de identificação do que pode dar errado num projeto ou programa, e formas de mitigação dos riscos (cf. CAFOR, 2007, p. 208).

7 Há sutis e importantes diferenças que serão mais adiante exploradas entre a noção de outcome [estado positivo alcançado] e outras noções como objective [objetivo], result [resultado], goal [fim, meta].

Horizontes Antropológicos, Porto Alegre, ano 20, n. 41, p. 87-115, jan./jun. 2014 
outcome; UE [União Europeia] com objective e result. ${ }^{8}$ Em suma: a CAFOD precisava alinhar-se às metodologias utilizadas pelas outras grandes agências e o treinamento - pensado como uma capacitação das equipes na CAFOD - nada mais era do que o dar a ver um modelo a partir do qual os funcionários deveriam operar, e saberes que deveriam mobilizar para aumentar as chances de a organização estabelecer relações com outras agências financiadoras.

Não apenas os parceiros deveriam ser capacitados, mas também os funcionários da própria organização. Bart, em entrevista, expressou a seguinte opinião sobre uma gerente de programa da divisão internacional: "Ela é uma boa garota, mas não tem as competências necessárias.” Isto refletia a sua visão geral sobre os funcionários de programa:

A CAFOD não tem funcionários treinados nas competências necessárias. Eles sabem línguas, têm conhecimento em áreas específicas como saúde, mas nenhum conhecimento em sistemas, nenhuma experiência em apoio de parceiros de programas. As organizações americanas têm muito mais treinamento nessas competências... A CRS (Catholic Relief Services) [dos Estados Unidos] é muito mais técnica. (Bart, entrevista em junho de 2008).

Bart acreditava que as agências de desenvolvimento estariam melhor preparadas se contratassem pessoas advindas da área de administração, cujas ferramentas permitem uma atuação considerada mais eficiente. Por isso, ao contrário do que fazia com os development workers [profissionais do desenvolvimento] na CAFOD, Bart exaltava aqueles vindos do setor privado, como Philip, gerente da equipe PCM: "Ele não é um profissional da área de desenvolvimento. O setor privado é mais focado em resultados. As coisas têm que mudar no [setor do] desenvolvimento.”

Para Bart, um planejamento feito de maneira competente era a única forma de efetivamente erradicar a pobreza e fazê-lo através de uma relação genuinamente igualitária com as organizações parceiras:

O ciclo PCM é feito em conjunto, nós ao lado de nossos parceiros. A CAFOD não pode ter uma mentalidade de torre de marfim, uma mentalidade de

8 O próprio manual do PCM da CAFOD (2007, p. 231) cita as obras das quais foi tirado, Big Lottery e Trócaire: Explaining the difference your project makes: A BIG guide to using an approach (Big Lottery Fund/Triangle Consulting, May 2006); From the project model to the programmatic approach (Trócaire, Aug. 2005); Guiding document for new Trócaire Programme Approval System (Trócaire, Oct. 2005).

Horizontes Antropológicos, Porto Alegre, ano 20, n. 41, p. 87-115, jan./jun. 2014 
financiador-beneficiário. Nós precisamos fazer programação horizontal, não o controle de programas verticais. Se três parceiros trabalham juntos, teremos impacto melhor... "Não", as pessoas dizem, “nós temos nossa identidade!”... Mas você não perde sua identidade, você abre mão de um pouco de autonomia. Nós trabalhamos em parceria. O PCM não deve ir contra isso de forma alguma. Outcomes e indicators devem ser acordados na base, numa matriz simplificada. É uma prática orientada para a base, é simples. Os parceiros a apreciam. Eles sentem que é um reforço positivo para seu trabalho. A matriz é baseada em pensamento lógico... desde que todos acreditem nela, ela funciona. (grifo meu).

O bom planejamento feito lado a lado com organizações parceiras, na base, garante o resultado almejado e a eficiência do projeto. Indispensável, todavia, é a crença conjunta no poder do pensamento lógico, expresso através de uma matriz simplificada, desenvolvida em oficinas com a presença do indispensável flip-chart. Um objeto como o flip-chart - espécie de lousa portátil composta por um bloco de papel em branco apoiado sobre um cavalete, comumente utilizado em oficinas e reuniões - é importante porque permite inscrever coletivamente no papel uma composição do social, em processo dito participativo, decisiva para o desenho da intervenção social. O modelo de matriz utilizado pela CAFOD, sempre em formato de tabela, era o seguinte:

Tabela 1. Modelo de matriz utilizado pela CAFOD.

Meta do Programa:

Meta do Projeto:

Quais mudanças específicas o projeto pretende operar? (anticipated outcomes [efeito antecipado])
Como você saberá se estas mudanças estão acontecendo / aconteceram? (indicadores)
Quais atividades específicas serão realizadas para operar esta mudança? (atividades)

As habilidades que Bart considerava importantes, aquelas que ele acreditava serem de fato necessárias para combater a pobreza com eficiência e evitar uma mentalidade de torre de marfim, iam além da simples capacidade de gerência; e incluíam a do engenheiro social de traçar rumos futuros de forma estratégica. A ideia subjacente à suposta falta de competência dos funcionários de programa (os especialistas em development), e à presumida competência 
do funcionário focado em resultados (o profissional do setor privado), era a mesma que instituía como necessária a capacitação - o dar a ver um modelo consoante o qual se deveria operar, os saberes que se deveriam mobilizar e, principalmente, a familiarização com uma forma determinada de pensar.

Lévi-Strauss (1976, p. 36), no célebre texto em que explora a diferença entre o pensamento científico e mítico, que considera nada mais do que "dois níveis estratégicos onde a natureza se deixa atacar pelo conhecimento científico”, afirma que, ao contrário do bricoleur que deve se arranjar com os meios-limites (um conjunto restrito de ferramentas, não definido por um projeto), o engenheiro concebe e procura ferramentas na medida de seu projeto (Lévi-Strauss, 1976, p. 38-39). O sistema PCM nada mais é do que uma ferramenta elaborada com um projeto como horizonte, que como explicitado no CAFOD 2010, era a "mudança nas vidas das pessoas". Note-se: o projeto não consiste na modificação de estruturas sociais, reorganização do sistema mundial, extinção da sociedade de classes, ou mesmo no que era antigamente enunciado na organização - o combate às "estruturas de pecado". O projeto atual é o de operar mudanças pontuais na vida das pessoas, não muito diferente do encontrado em outras grandes agências de desenvolvimento envolvidas em emaranhados institucionais de combate à pobreza (Morawska Vianna, 2010). As ferramentas concebidas na medida de tal projeto têm a importante particularidade de se adaptar às especificidades de lutas localizadas dos mais diversos tipos - indígenas, mulheres portadoras de HIV, quilombolas, grupos em periferias de cidades. A matriz - segmentada em caixas para goal, outcomes, indicators, activities - enquadra qualquer tipo de problema, permitindo que especificidades de cada projeto caibam dentro do horizonte comum de trabalho, na área de atuação definida como development. Isso permite, por um lado, que organizações com atuações específicas tenham para si canalizados recursos e se enganchem a emaranhados institucionais de longo alcance, e, de outro lado, que as organizações internacionais estendam a sua presença em muitos lugares, conectando-se a parceiros com lutas extremamente diferentes entre si.

Assim, o treinamento sobre como fazer relatórios de boa qualidade revelou-se uma verdadeira lição em engenharia social - um nível estratégico onde a sociedade se deixa atacar. Algumas das primeiras lições de Bart no treinamento eram expressas com afirmações como: "Metas devem ser realistas. Você começa com outcomes, seis no máximo. Outcomes são logicamente conectados.” Bart menciona como uma técnica de planejamento como o

Horizontes Antropológicos, Porto Alegre, ano 20, n. 41, p. 87-115, jan./jun. 2014 
problem tree [árvore de problemas] dava melhor entendimento acerca da conexão lógica entre outcomes. Apesar de apenas mencioná-la no treinamento, tal técnica era explorada no manual do PCM, e é bastante expressiva do tipo de procedimento que os especialistas em desenvolvimento colocam em prática com vistas a traçar planos estratégicos de intervenção social e assim operar "mudanças nas vidas das pessoas".

A árvore de problemas, idealmente desenvolvida através de método participativo, contém dois importantes elementos: a visualização de relações causais num diagrama e o estabelecimento de hierarquia de causa e efeito entre problemas. O exemplo oferecido no manual é na área de segurança alimentar (Figura 1).

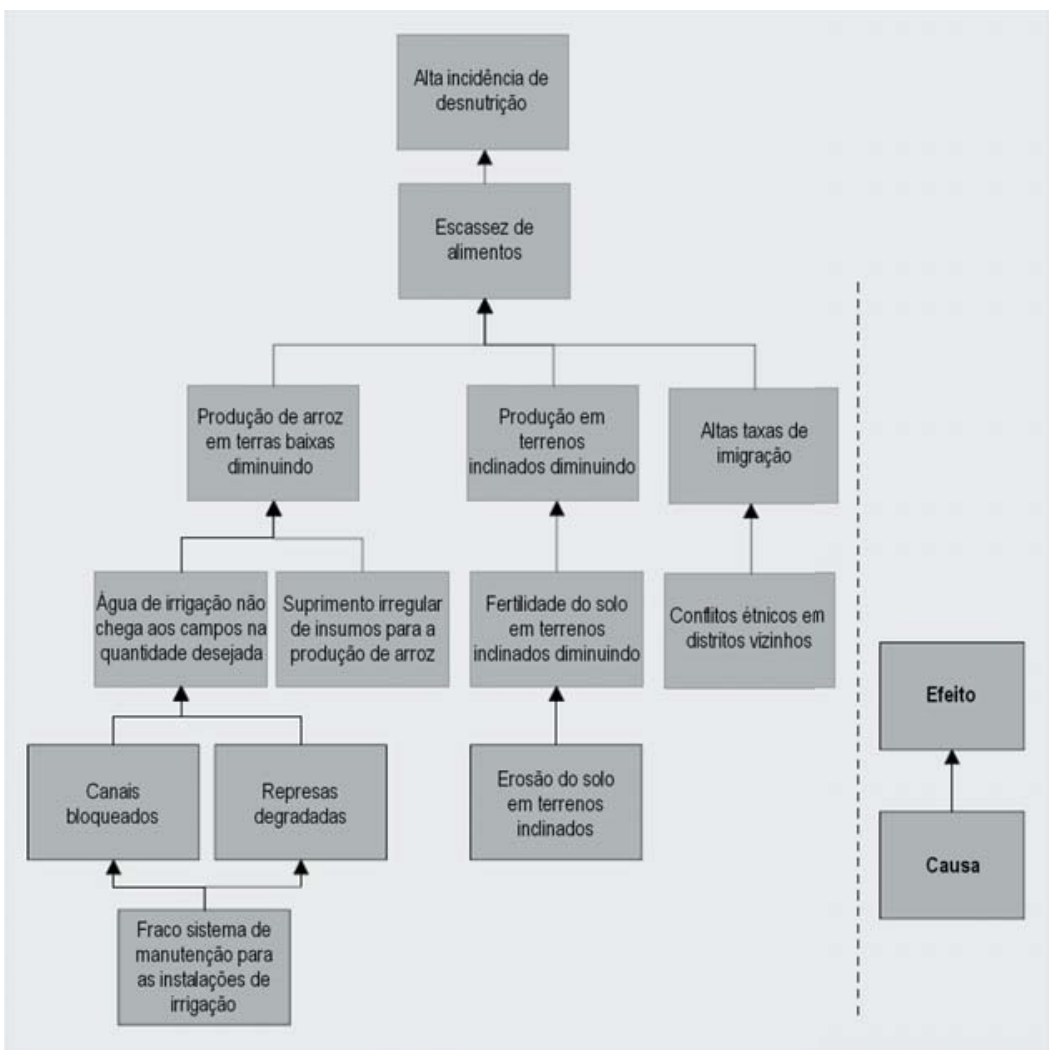

Figura 1. Diagrama de problemas (CAFOD, 2007, p. 244). 
Uma lista de problemas é disposta em quadrados, organizados entre si de forma que se identifique a causa original do problema maior (efeito final). Por exemplo, uma alta incidência de desnutrição é causada remotamente pela má manutenção dos sistemas de irrigação, erosão do solo nas montanhas e conflitos étnicos em distritos vizinhos. Entre estas causas e o efeito final (a ser combatido), outros problemas são dispostos em relação de causa e efeito entre si.

O mesmo diagrama sofre uma transformação, descrita da seguinte maneira: “A tradução da situação negativa na árvore de problema em um estado positivo alcançado (os outcomes), por exemplo ‘baixa produção de arroz', é convertido em 'produção de arroz melhorada'.” O diagrama de causas e efeitos torna-se um diagrama de meios e fins a partir de um exercício linguístico em que um problema é convertido num estado positivo alcançado, isto é, um outcome (Figura 2).

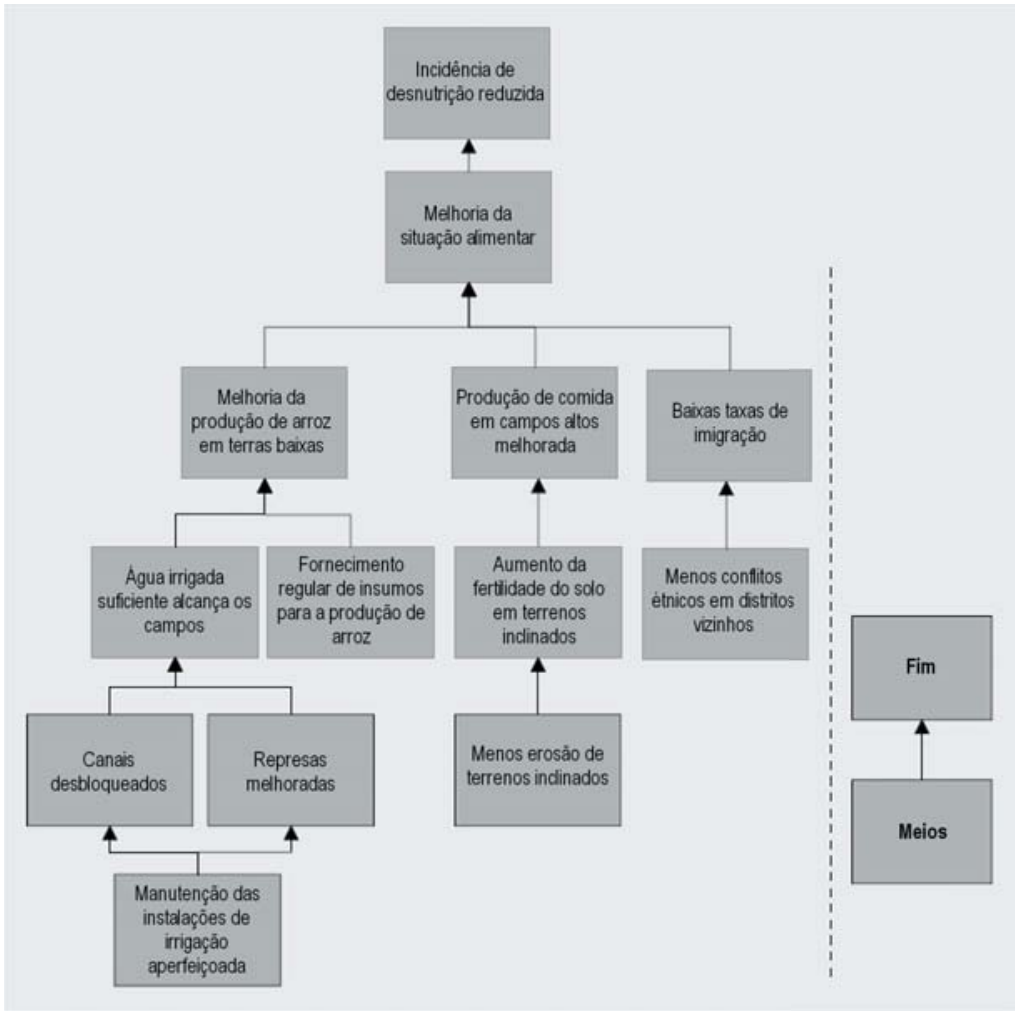

Figura 2. Diagrama de outcomes (resultados) (CAFOD, 2007, p. 245). 
A composição inscrita no diagrama permite que se desenhe uma estratégia de "ataque à sociedade": a solução de um problema baseado num processo lógico, simples, que segundo Bart os parceiros apreciam como um reforço de seu trabalho. O problema maior "alta incidência de desnutrição" torna-se a meta "incidência de desnutrição reduzida"; uma de suas causas, a "diminuição de produção de arroz em terras baixas” torna-se o outcome "produção de arroz em terras baixas aumentada”. Os outcomes são então agregados para que caibam dentro da matriz, oferecendo um diagrama intitulado Clustering of outcomes [Aglomeração de resultados esperados] (Figura 3).

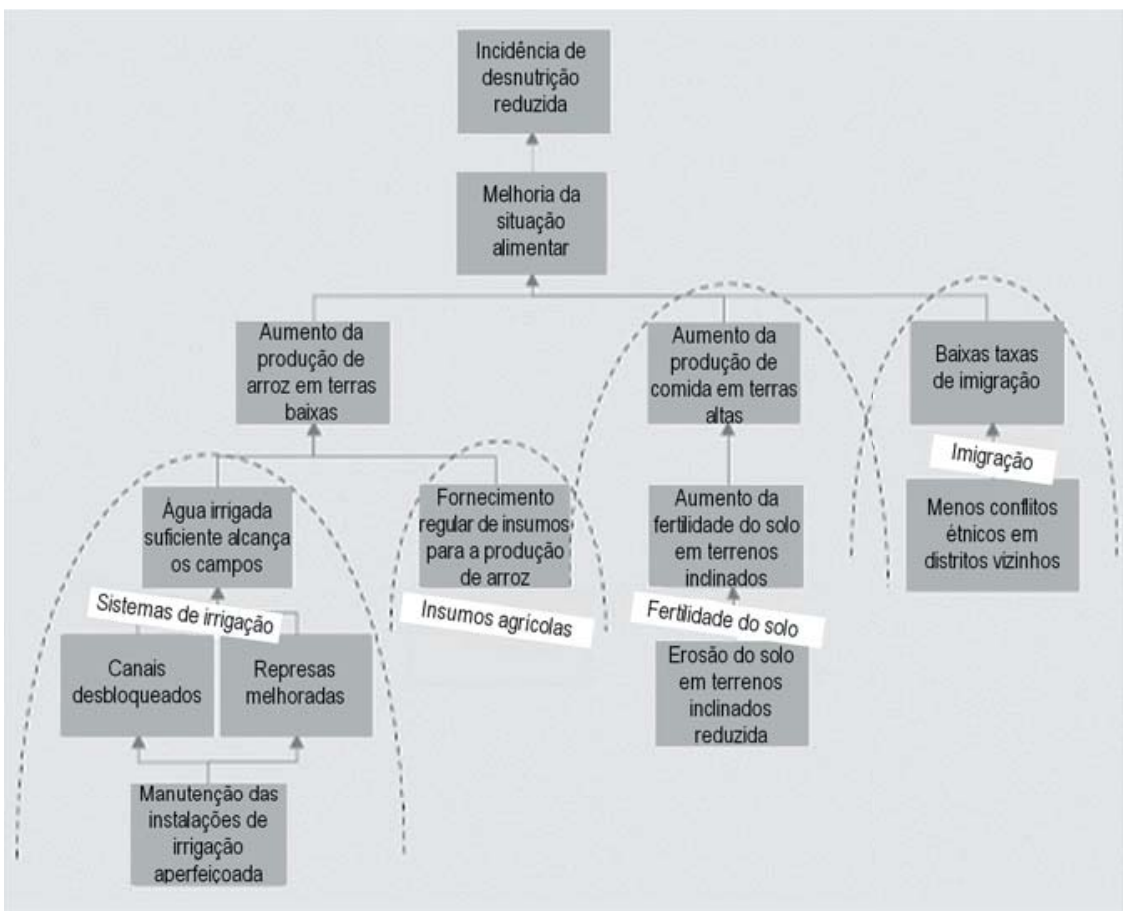

Figura 3. Diagrama de aglomeração de outcomes (CAFOD, 2007, p. 245).

Nesse exemplo, são quatro os outcomes que emergem do exercício, relacionados a: sistema de irrigação; produção agrícola; fertilidade do solo; e 
imigração. A transformação de problemas em outcomes e a sua posterior organização em formato de matriz tem idealmente o intuito de calcar as ações sobre um pensamento lógico, o que permite traçar estrategicamente os rumos da ação e mensurar o resultado da intervenção, ou seja, se o estado positivo determinado no desenho do projeto foi de fato alcançado.

Percebe-se assim que a engenharia social envolve em grande medida um procedimento lógico em torno de formulações linguísticas. Bart não escondia sua irritação com os outcomes encontrados no WebPromise, a base de dados da CAFOD, que considerava longos e confusos. Daí seu treinamento consistir sobretudo na aplicação de exercícios linguísticos.

Um deles visava aprimorar alguns dos outcomes encontrados do WebPromise:

Iabela 2. Esquema de outcomes definidos e aprimorados.

\begin{tabular}{|c|c|}
\hline Outcomes definidos & Outcomes aprimorados \\
\hline $\begin{array}{l}\text { Apoiar comunidades e organizações } \\
\text { de base, as sanghas budistas e } \\
\text { membros de todas as outras fés, a } \\
\text { exercer papel ativo no processo de } \\
\text { desenvolvimento, para criar uma } \\
\text { sociedade civil saudável em Myanmar. }\end{array}$ & $\begin{array}{l}\text { Uma coexistência pacífica de grupos de } \\
\text { base religiosa em Myanmar. } \\
\text { Ou } \\
\text { Uma sociedade civil forte em Myanmar } \\
\text { através de comunidades e organizações de } \\
\text { base. }\end{array}$ \\
\hline $\begin{array}{l}\text { Apoiar três delegados indígenas } \\
\text { à Convenção sobre Alterações } \\
\text { Climáticas da ONU (UNFCCC) em } \\
\text { Bali, 3-14 dezembro de 2007, para } \\
\text { que possam atender à conferência } \\
\text { e receber treinamento especializado } \\
\text { para que no futuro sejam capazes de } \\
\text { participar e influenciar negociações em } \\
\text { alterações climáticas na ONU. }\end{array}$ & $\begin{array}{l}\text { Três delegados indígenas informados para } \\
\text { que lidem com alterações climáticas e se } \\
\text { engajem com órgãos da ONU quanto às } \\
\text { alterações climáticas. }\end{array}$ \\
\hline $\begin{array}{l}\text { Capacitar os funcionários HIVIAids a } \\
\text { gerenciar e prover assistência e apoio } \\
\text { a pessoas vivendo com HIV e Aids. }\end{array}$ & $\begin{array}{l}\text { Apoio de qualidade a pessoas vivendo com } \\
\text { HIVIAids e suas famílias. }\end{array}$ \\
\hline
\end{tabular}

Bart dizia: "Mantenha as frases simples. Evite uma terminologia que soa bem, mas não diz nada.” A modificação de "capacitar funcionários a gerir e 
prover apoio a pessoas vivendo com HIV/Aids" para "apoio de qualidade para pessoas vivendo com HIV/Aids e suas famílias" evidenciava que "dizer nada” ou "dizer algo" estava menos relacionado ao conteúdo das frases do que com a precisão da formulação linguística envolvida no procedimento lógico acima descrito.

Como se medem outcomes? "Medimos outcomes com indicadores." No treinamento, Bart se utilizava do exemplo de parceiros: "No Brasil, um dos programas conseguiu financiamento da União Europeia. Você pergunta para eles o que mudou para os jovens nas favelas com o treinamento em liderança, sua resposta é 'Eles gostam' ou 'Não sabemos'.” Outro exemplo: “Em Bangladesh, eles são extremamente profissionais, especialmente em organizações com pessoal mais treinado. Todavia, quando se pergunta para as pessoas sobre indicadores, elas contam estórias.” Bart insistia na necessidade de se trabalhar mais sistematicamente, mais objetivamente:

Dez pessoas diferentes lhe dirão dez estórias diferentes. Temos que ser mais objetivos. Em desenvolvimento as pessoas não gostam de quantificar as coisas, é uma "palavra feia". Mesmo seus indicadores qualitativos têm de ser mensurados. Um indicador não é uma verdade, é só uma indicação do progresso que você faz. Não significa que você atingiu seu objetivo, é só uma indicação.

Sobre os indicadores, alguns conselhos: delegar a alguém a mensuração dos outcomes; realizar a chamada baseline research [pesquisa de base] no começo do programa; estabelecer indicadores mensuráveis:

Três ou quatro indicadores por outcome. Você pode se enganar, mas com quatro você está a salvo. Com mais, é o inferno. O projeto da União Europeia em Ruanda tinha 36 indicadores. Você torna sua vida um inferno. Faça algo simples. Faça indicadores que os parceiros também podem medir. Nós não medimos calorias, mas a perda de peso de crianças é mais fácil. Como medimos violência com um teste psicológico complicado ou com quantos casos foram denunciados à polícia? Qual é mais fácil?

Mais uma tabela foi apresentada com indicadores encontrados no WebPromise com exemplos de como se poderia aprimorá-los: 
Iabela 3. Esquema de indicadores definidos e aprimorados.

\begin{tabular}{|c|c|}
\hline Indicadores definidos & Indicadores aprimorados \\
\hline $\begin{array}{l}\text { Número de violações em } \\
\text { direitos humanos }\end{array}$ & $\begin{array}{l}\text { No fim da intervenção, veremos um aumento de } \\
50 \% \text { dos casos trazidos a público em violações de } \\
\text { direitos humanos cometidos pelas forças rebeldes } \\
\text { e governamentais dos distritos A, B e C para as } \\
\text { comissões de direitos humanos (identificadas) } \\
\text { e organizações de direitos humanos (é preciso } \\
\text { estabelecer uma informação-base com isso). }\end{array}$ \\
\hline $\begin{array}{l}\text { Redução na incidência } \\
\text { de doenças evitáveis nas } \\
\text { comunidades alvo }\end{array}$ & $\begin{array}{l}\text { No fim da intervenção veremos uma diminuição em } \\
40 \% \text { nas três principais doenças evitáveis trazidas } \\
\text { às clínicas de saúde primária (isto é, malária, diarreia } \\
\text { e sarampo) nos distritos A e B por membros das } \\
\text { comunidades alvo A, B, C... (é preciso estabelecer } \\
\text { informação de referência). }\end{array}$ \\
\hline $\begin{array}{l}\text { Pessoas vivendo com HIV } \\
\text { e Aids e suas famílias, } \\
\text { alvo do programa, fazendo } \\
\text { uso dos serviços de saúde } \\
\text { disponíveis }\end{array}$ & $\begin{array}{l}\text { No fim da intervenção veremos um aumento em } 25 \% \\
\text { de pessoas vivendo com HIV e Aids frequentando } \\
\text { as clínicas de saúde identificadas nos distritos } \\
\text { identificados solicitando consultas com médicos. (de } \\
\text {...\% agora). }\end{array}$ \\
\hline
\end{tabular}

O grande desafio, segundo Bart, era tomar para si o crédito da mudança, já que há muitos outros fatores envolvidos quando da implementação de um projeto, muitas vezes imprevistos e fora do controle dos funcionários envolvidos. Uma forma de fazê-lo, mais difícil e trabalhosa, estava contida na seguinte sugestão: "Você deve mapear os outros fatores", isto é, realizar risk analysis [análise de risco], stakeholder analysis [análise de partes interessadas], e assim por diante. A outra forma era simplesmente estabelecer no desenho do programa metas alcançáveis: “Coloque metas nos seus indicadores - isso cria accountability [responsabilização], mas não metas inalcançáveis. Se eu estabeleço metas, sou responsável por elas. O aumento em 30\% é seguro, melhor do que dizer $40 \%$, uma meta que não se pode alcançar.” A medida do sucesso depende também da elaboração de metas possíveis de serem alcançadas.

De acordo com a lógica da engenharia social, um bom planejamento permite não apenas um projeto estruturado, como também uma maior accountability [responsabilização]. A matriz torna-se a referência contra a qual se 
avalia o projeto, e dentro do mundo do desenvolvimento há vários modelos utilizados. O mais disseminado é a logical framework [matriz lógica] (ou log-frame), desenvolvida no fim dos anos 1960 para o USAID, e utilizado desde então por grandes financiadoras governamentais e não governamentais que trabalham com projetos de desenvolvimento. ${ }^{9} \mathrm{~A}$ log-frame é um pouco mais complexa que a matriz de outcomes da CAFOD, e sua lógica é baseada na ideia de uma sequência de eventos: inputs [entradas] possibilitam activities [atividades], que provocam outputs [saídas], que cumprem purposes [propósito] (equivalentes aos outcomes aqui explorados), que alcançam a goal [meta]. Não cabe aqui explicar em detalhes a log-frame, apenas mencionar que também ela é desenvolvida a partir do mecanismo de conversão da relação de causa e efeito em meios e fins (através da árvore de problemas). Tanto a matriz de outcomes como a log-frame expressam uma sequência de hipóteses de forma que a informação preponderante é o fim, a meta a ser alcançada. Isso implica que o futuro (o estado positivo alcançado) é a referência da ação presente.

Em 2003, a BOND, uma rede de mais de 270 ONGs de desenvolvimento no Reino Unido, da qual a CAFOD também faz parte, produziu uma pequena publicação com instruções gerais sobre como desenvolver uma log-frame, como orientação a seus membros pelo fato de ser este o modelo usado pelo DFID [agência britânica de desenvolvimento internacional]. Nela, lia-se:

O que eu preciso para produzir uma matriz lógica?

- uma quantidade de grandes folhas de papel (preferencialmente folhas de flip-chart);

- lápis, apagador e notas de "Post-it" ou cartões, para que se possa ajustar e consertar à medida que se avança;

- um lugar para trabalhar sem distrações;

- idealmente, alguém com quem discutir e trocar ideias sobre a matriz;

- o máximo de informação possível sobre o projeto planejado

- fazer preferencialmente “no campo”. (BOND, 2003, p. 3).

As ferramentas sugeridas para o desenho da matriz implicavam um trabalho solitário, sem distrações, com informações à mão e algum eventual

9 Cf. Norad (1999), citado como fonte de consulta pelo manual do PCM da CAFOD (2007).

Horizontes Antropológicos, Porto Alegre, ano 20, n. 41, p. 87-115, jan./jun. 2014 
interlocutor, além do flip-chart, aqui não para uma composição coletiva, mas como forma de visualização do procedimento lógico e do resultado final em forma de matriz. Essa era de fato a forma mais comum de produção das matrizes:

A realidade das propostas de financiamento e de completar matrizes lógicas geralmente implica um funcionário de escritório no Reino Unido tentando resumir um esboço de projeto para uma solicitação de financiamento. Todavia, se usada corretamente como uma ferramenta de planejamento, a abordagem de matriz lógica deve ser desenvolvida primeiro pela, ou trabalhando próximo a, pessoa mais intimamente envolvida com a implementação do projeto, que mais provavelmente será o coordenador do projeto ou a organização parceira no exterior $[\ldots]$.

Escrever matrizes lógicas no Reino Unido não é tão participativo, o que levou a críticas à matriz lógica como uma ferramenta de planejamento. Idealmente ela deveria ser produzida no país para que durante o estágio de planejamento abordagens participativas possam ser usadas para alimentar o log-frame à medida que é desenvolvida. Enquanto os beneficiários de projeto podem não se identificar facilmente com o conceito de abordagem de matriz lógica, eles podem identificar os fatores que são críticos ao sucesso do projeto, bem como os mais apropriados indicadores de progresso. (BOND, 2003, p. 3, grifo meu).

Admite-se que a "realidade das solicitações de financiamento" - o mundo das agências de desenvolvimento -, leva a ferramenta de planejamento a ser predominantemente utilizada por um desk officer [funcionário de escritório] no Reino Unido. Ao mesmo tempo, há o reconhecimento da importância da participação dos parceiros no processo de desenvolvimento da matriz, fruto das muitas críticas aos profissionais do desenvolvimento ao longo dos anos, por ignorarem a perspectiva daqueles para quem as intervenções são desenhadas. Como conciliar a necessidade de participação dos beneficiários (e organizações de base) no processo de planejamento com o fato de que "beneficiários de projetos não se identificam com o conceito de matrizes”?

A insistência aqui em explorar as enunciações de Bart (em seu treinamento e entrevista) se dá porque elas expressam uma apologia aos princípios da engenharia social, segundo os quais haveria a possibilidade de organizações de base se identificarem com o conceito de matrizes caso tivessem a facilitação necessária para tanto. Se a erradicação da pobreza estava condicionada 
a programas e projetos bem desenhados, cuja única condição era a aplicação de um pensamento lógico, daí decorria que era apenas preciso dar oportunidade para os parceiros o fazerem através de oficinas de capacitação e de planejamento conjunto. Nada que um bom facilitador não pudesse resolver - daí ele enfatizar em sua entrevista a sua competência como facilitador e sua crítica à mentalidade da torre de marfim. A matriz era orientada para a base porque era simples, direta, lógica, mas para que funcionasse era necessária a crença comum em seus princípios; era necessária a identificação por todas as partes envolvidas com o conceito de matrizes.

Compreende-se assim que oficinas participativas de planejamento conjunto não existem como forma de se apreender a perspectiva dos beneficiários ou organizações de base, mas são instâncias em que se apresenta e exercita uma certa forma de pensar - um nível estratégico de se atacar a sociedade. Nelas, abre-se a possibilidade aos parceiros de participarem do trabalho de engenharia social, não apenas contribuindo com informações a que não se tem acesso a partir dos escritórios no Reino Unido, como sobretudo utilizando as ferramentas de planejamento em que se baseia o trabalho das grandes agências de financiamento - os saberes técnico-burocráticos que se mobilizam para se conectarem a emaranhados institucionais de longo alcance.

A afirmação de que beneficiários (e organizações de base) não se identificam com matrizes - a inscrição no papel do projeto tal qual se passa no cotidiano (em formato de tabela) -, não está portanto em alguma suposta crença por parte dos engenheiros sociais de que beneficiários prescindem de pensamento lógico. Por um lado, a afirmação é baseada em cem estórias contadas por funcionários a partir da experiência em cem lugares, transformadas em generalizações: “os parceiros não são objetivos, contam estórias”; "deve-se manter os indicadores simples para que parceiros consigam medi-los"; "parceiros tendem a focar em atividades”. Por outro lado, a explicação que um engenheiro social oferece para a não identificação de beneficiários (e organizações de base) a matrizes está na pouca familiaridade com ferramentas de aplicação de procedimento lógico à solução de problemas. Arrisco, porém, uma outra explicação baseada numa lógica diferente da que instaura o próprio problema: a não identificação às matrizes pode ser compreendida pela temporalidade subjacente ao trabalho de engenharia social aqui descrito. 


\section{A lógica das matrizes e seu descompasso com o mundo dos beneficiários}

O eixo de referência para as ações de um projeto é o fim de seu ciclo, representado pelo outcome (estado positivo alcançado). O procedimento que transforma o problema em um outcome cria uma composição do socius, representada pela matriz, que supõe uma sequência de eventos, pensadas não em termos de causa e efeito, mas fim e meios, ou seja, uma meta desejada no presente será alcançada desde que atores A, B e C operem as ações X, Y, Z. A composição é em si diacrônica, imaginada como uma sequência de eventos inscritos no tempo, embora haja o reconhecimento de que no mundo dos beneficiários os eventos não se passam como previsto:

Nenhum projeto de desenvolvimento existe num vácuo social. É importante que a situação desejada futura seja descrita de tal modo que torna possível verificar num estágio posterior em que medida o projeto foi bem sucedido em relação a seus objetivos e os grupos-alvo. (Norad, 1999, p. 7).

Nenhum projeto existe num vácuo social, mas a construção da matriz no flip-chart exige que se isole o objeto da intervenção social de forma que se suponha o vácuo social para que o projeto se dê da forma como desenhado.

Importante diferenciar composições fixas da matriz de projeto com as composições móveis que ordenam as ações das organizações de base que lidam diretamente com os beneficiários.

Como já mencionado, considera-se uma composição aquilo que os atores vislumbram como o campo do possível, definido por elementos (pessoas, coisas, categorias, nomes) recorrentemente postos em relação dentro de fronteiras de mundo continuamente delineadas, a cada atualização. As composições, constantemente constituídas no dia a dia e referência para a ação, são sucessivamente reconfiguradas a partir das conexões que efetivamente se dão no mundo dos beneficiários. Inscritas na diacronia, elas são intrinsecamente maleáveis e efêmeras. No caso da composição representada pela matriz, esta é iterada sucessivamente na forma como projetada, e não redelineada a cada atualização (a cada atividade realizada). Há o prolongamento no tempo de uma mesma composição (representada pela matriz) como referência para a ação. Eis a temporalidade subjacente ao trabalho de engenharia social: uma composição (representada pela matriz) que carrega em si uma dimensão diacrônica (a sucessão de eventos) é iterada sucessivamente tendo como suposto o vácuo social (sempre sincrônico). 
Ora, isto é diferente do que se passa no dia a dia dos projetos, e aqui nos aproximamos da explicação de por que os parceiros não se identificam com o conceito de matrizes. Entre os que implementam os projetos, o trabalho é predominantemente organizado em torno de um calendário de atividades. Isso provoca, à medida que os eventos se sucedem, a reconfiguração sucessiva das composições que são referência para a ação cotidiana; ou seja, as composições estão inscritas na diacronia e consequentemente há uma constante adaptação aos imprevistos. O trabalho é marcado pela reação às contingências, o que é tido pelos engenheiros sociais como uma atuação não estratégica.

O olhar estratégico, que baseia as ações numa matriz rígida (iterada sucessivamente da forma como projetada) apresenta a desvantagem de não permitir a reação a imprevistos, senão após seu fim, como medida de verificação do sucesso (ou fracasso) do projeto. Dois são os mecanismos formalmente estabelecidos para que haja uma adaptação às contingências que emergem. Um deles é a realização de análises para prever desvios e riscos e assim incorporá-los à matriz. O outro é o ajuste periódico da matriz a eventuais mudanças, o que geralmente ocorre na revisão anual do planejamento. Sendo a matriz simultaneamente referência para a ação e medida de verificação do projeto, quanto mais ela consegue antecipar possíveis riscos (os imprevistos e desvios a si mesma), melhor ela se torna medida de si, ou seja, mais provavelmente apontará o seu sucesso, decidido a partir de seus próprios termos.

A matriz do Projeto Tarrafa encontrada no WebPromise (Tabela 4) originalmente contém um texto em português, redigido pelos parceiros em Recife e Olinda, e outro em inglês, traduzido pelos técnicos da CAFOD. É interessante perceber como no processo de tradução da meta (goal) alguns elementos importantes perdem-se:

Project goal: children and young people in the favelas of Recife adopt positive values such as citizenship and engage with their communities to defend their right to a life free from violence, poverty and exclusion.

Meta do projeto: desenvolver um programa em rede, de forma integrada e complementar, que possa contribuir para a efetivação do sistema de garantias de direitos da criança e do adolescente promover a inclusão de crianças e adolescentes em situação de risco pessoal e social através de uma pedagogia participativa e libertadora e da ação complementar junto à família, escola e comunidade. 
Tabela 4. Project matrix / matriz de projeto.10

Project ID: BRA458
Project Title: Projeto Tarrafa - Street Children's Centres in Recife and Olinda

Meta do Projeto: Desenvolver um programa em rede, de forma integrada e complementar, que possa contribuir para a efetivação do sistema de garantias de direitos da criança e do adolescente promover a inclusão de crianças e adolescentes em situação de risco pessoal e social através de uma pedagogia participativa e libertadora e da ação complementar junto à família, escola e comunidade.

\begin{tabular}{|c|c|c|}
\hline $\begin{array}{l}\text { Quais mudanças } \\
\text { específicas o projeto } \\
\text { pretende operar? } \\
\text { (anticipated outcomes } \\
\text { [efeito antecipado]) }\end{array}$ & $\begin{array}{l}\text { Como você saberá } \\
\text { se estas mudanças } \\
\text { estão acontecendo } \\
\text { / aconteceram? } \\
\text { (indicadores) }\end{array}$ & $\begin{array}{l}\text { Quais atividades } \\
\text { específicas serão realizadas } \\
\text { para operar esta mudança? } \\
\text { (atividades) }\end{array}$ \\
\hline $\begin{array}{l}\text { 1.1. Crianças e } \\
\text { adolescentes em situação } \\
\text { de risco têm sua cidadania } \\
\text { construída e resgatada. } \\
\text { 1.2. Crianças e jovens } \\
\text { têm crescente consciência } \\
\text { crítica, participação e } \\
\text { engajamento efetivo na } \\
\text { vida comunitária. } \\
\text { 1.3. Crianças e jovens têm } \\
\text { melhor relacionamento } \\
\text { entre os educandos e suas } \\
\text { famílias e mais respeito } \\
\text { pela comunidade e por } \\
\text { uma cultura da paz. }\end{array}$ & $\begin{array}{l}\text { 1. Aumento no número de } \\
\text { crianças e jovens com sua } \\
\text { auto-estima melhorada } \\
\text { e conscientes das } \\
\text { questões que afetam sua } \\
\text { comunidade, como saúde } \\
\text { e meio-ambiente. }\end{array}$ & $\begin{array}{l}\text { 1.1. Oficinas para jovens } \\
\text { sobre cidadania. } \\
\text { 1.2. Oficinas para jovens } \\
\text { sobre drogas, higiene, } \\
\text { prevenção de doenças } \\
\text { (tuberculose, hanseníase, } \\
\text { leptospirose), meio- } \\
\text { ambiente, sexualidade e } \\
\text { DST. } \\
\text { 1.3. Visitas regulares } \\
\text { a famílias para } \\
\text { aconselhamento e apoio; } \\
\text { encontros regulares para as } \\
\text { famílias nos centros. }\end{array}$ \\
\hline $\begin{array}{l}\text { 2.1. Crianças e } \\
\text { adolescentes reintegrados } \\
\text { na sociedade através } \\
\text { de iniciativas populares } \\
\text { em que eles participam } \\
\text { na elaboração e } \\
\text { implementação. } \\
\text { 2.2. Crianças e } \\
\text { adolescentes com auto- } \\
\text { estima melhorada através } \\
\text { de atividades artísticas e } \\
\text { culturais. }\end{array}$ & $\begin{array}{l}\text { 2. Aumento no número } \\
\text { de crianças e jovens } \\
\text { participando das atividades } \\
\text { do projeto que se sentem } \\
\text { mais integrados na } \\
\text { comunidade e aprenderam } \\
\text { habilidades vocacionais. }\end{array}$ & $\begin{array}{l}\text { 2.1. Oficinas de leitura, } \\
\text { artesanato, teatro, } \\
\text { serigrafia, pintura e } \\
\text { treinamento vocacional. } \\
\text { 2.2. Treinamento esportivo } \\
\text { (futebol, capoeira, dança, e } \\
\text { outros esportes). }\end{array}$ \\
\hline
\end{tabular}

${ }^{10}$ Dados do WebPromise em julho de 2008. Foi aqui reproduzida apenas a versão da matriz em português.

Horizontes Antropológicos, Porto Alegre, ano 20, n. 41, p. 87-115, jan./jun. 2014 


\begin{tabular}{|c|c|c|}
\hline $\begin{array}{l}\text { 3. Crianças e adolescentes } \\
\text { envolvidos e interessados } \\
\text { no processo educativo } \\
\text { como parte de sua } \\
\text { formação e treinamento } \\
\text { através de atividades } \\
\text { conjuntas com escolas } \\
\text { locais. }\end{array}$ & $\begin{array}{l}\text { 3. Número de oficinas } \\
\text { conjuntas com escolas } \\
\text { demonstra o envolvimento } \\
\text { de instituições de ensino } \\
\text { locais no trabalho com } \\
\text { crianças em situação de } \\
\text { risco da comunidade. }\end{array}$ & $\begin{array}{l}\text { 3.1. Classes suplementares } \\
\text { para crianças que não estão } \\
\text { frequentando a escola. } \\
\text { 3.2. Oficinas de direitos da } \\
\text { criança e adolescente para } \\
\text { professores e funcionários } \\
\text { das escolas. }\end{array}$ \\
\hline $\begin{array}{l}\text { 4. Moradores da } \\
\text { comunidade com maior } \\
\text { capacidade de realizar } \\
\text { trabalho para influenciar } \\
\text { políticas públicas que } \\
\text { busquem melhorar a } \\
\text { situação das crianças da } \\
\text { comunidade (saúde, água, } \\
\text { infra-estrutura). }\end{array}$ & $\begin{array}{l}\text { 4. Aumento no número } \\
\text { de jovens e comunidades } \\
\text { ativamente participando } \\
\text { em espaços públicos } \\
\text { trabalhando para achar } \\
\text { soluções locais para } \\
\text { proteger crianças e jovens } \\
\text { em situação de risco, e } \\
\text { também melhorar serviços } \\
\text { locais (saúde, água, infra- } \\
\text { estrutura). }\end{array}$ & $\begin{array}{l}\text { 4.1. Participação nos } \\
\text { Conselhos estaduais e } \\
\text { municipais dos direitos da } \\
\text { criança e adolescente. } \\
\text { 4.2. Eventos conjuntos com } \\
\text { crianças e com unidades } \\
\text { promovendo questões como } \\
\text { HIV e alfabetização. }\end{array}$ \\
\hline $\begin{array}{l}\text { 5. Os três centros têm } \\
\text { maior capacidade de } \\
\text { prestar serviços e melhorar } \\
\text { seu gerenciamento } \\
\text { institucional. }\end{array}$ & $\begin{array}{l}\text { 5.1. Funcionários } \\
\text { aperfeiçoam seus } \\
\text { sistemas de administração } \\
\text { e planejamento } \\
\text { para assegurar a } \\
\text { sustentabilidade de } \\
\text { projetos econômicos e } \\
\text { políticos. } \\
\text { 5.2. Avaliação produzida } \\
\text { e recomendações } \\
\text { implementadas. } \\
\text { 5.3. } 20 \text { educadores } \\
\text { treinados em questões } \\
\text { pedagógicas. } \\
\text { 5.4. Quantidade de } \\
\text { recursos assegurados com } \\
\text { a submissão de propostas } \\
\text { para fundos locais e } \\
\text { agências doadoras. }\end{array}$ & $\begin{array}{l}\text { 5.1. Reuniões de } \\
\text { monitoramento e } \\
\text { planejamento. } \\
\text { 5.2. Reuniões de avaliação. } \\
\text { 5.3. Treinamento } \\
\text { pedagógico para } \\
\text { educadores. } \\
\text { 5.4. Presença em atividades } \\
\text { de articulação (participação } \\
\text { em fóruns, reuniões de } \\
\text { conselhos de direitos). } \\
\text { 5.5. Preparação de } \\
\text { proposta a ser submetida } \\
\text { para fundos locais e } \\
\text { agência doadoras. } \\
\text { 5.6. Oficinas psicológicas. }\end{array}$ \\
\hline
\end{tabular}

A frase "contribuir para a efetivação do sistema de garantias de direitos da criança e do adolescente" carrega o vestígio de um Estado atuante; "uma pedagogia participativa e libertadora” revela a influência de Paulo Freire (que também é comum no mundo do desenvolvimento); e "ação complementar

Horizontes Antropológicos, Porto Alegre, ano 20, n. 41, p. 87-115, jan./jun. 2014 
junto à família, escola e comunidade” denota a inserção no bairro e a interface com estruturas do Estado. Na versão inglesa, a meta parece arrancada do contexto, resultando numa formulação que poderia ser utilizada para qualquer bairro pobre de uma grande cidade no sul (ou mesmo norte) geopolítico: "Crianças e jovens em adotam valores positivos como cidadania e participam da comunidade para defender seu direito a uma vida livre de violência, pobreza e exclusão.”

Como enfatizado, há o enquadramento de uma situação complexa num formato em que as informações se tornam passíveis de serem geridas e mensuradas. A matriz torna-se referência para a ação e medida do sucesso do projeto. Compreende-se a transformação operada na matriz em sua versão inglesa: a efetivação do sistema de garantias dos direitos das crianças e adolescentes envolve demasiados atores e fatores, para além do escopo do projeto, e é certamente mais difícil de mensurar do que, por exemplo, o aumento em $\mathrm{x} \%$ na participação de grupos específicos de crianças e adolescentes em atividades dentro de bairros determinados.

Tal meta é alcançada caso se atinjam cinco outcomes. Os dois primeiros estão bastante ligados às principais atividades em torno das quais revolve o trabalho dos grupos: visitas às famílias e oficinas oferecidas às crianças e adolescentes, que abordam temas como cidadania, saúde, leitura, artesanato, teatro, serigrafia, pintura, treinamento vocacional, esporte. O terceiro outcome relaciona-se à relação dos grupos com as escolas, e o quarto à sua relação com a comunidade. O quinto outcome refere-se ao aspecto que se tornou prioritário na relação de parceria com a CAFOD: o fortalecimento institucional.

A matriz supõe uma sucessão de eventos: oficinas de diferentes tipos acarretam crianças e adolescentes em situação de risco com a cidadania construída e resgatada (outcomes 1 e 2); aulas suplementares para crianças e adolescentes que não estão frequentando a escola acarretam crianças e adolescentes envolvidos e interessados no processo educativo como parte de sua formação e treinamento (outcome 3); eventos conjuntos com crianças e comunidades que promovem questões como HIV acarretam moradores da comunidade com maior capacidade de realizar trabalho para influenciar políticas públicas que busquem melhorar a situação das crianças da comunidade (outcome 4); reuniões de avaliação levam os três centros a terem maior capacidade de prestar serviços e melhorar seu gerenciamento institucional (outcome 5). 
Independentemente da avaliação de um engenheiro social quanto à presença de falácias nessas formulações, o que importa aqui é perceber o mecanismo que a engenharia social instaura. Idealmente, a matriz como referência para a ação é iterada sucessivamente da forma como projetada, tornando-se espécie de composição dura que se prolonga no tempo. No dia a dia, contingências emergem e mudam o rumo das atividades, o que as afasta do planejamento inicial (matriz). Na sede da agência financiadora esse descompasso é ajustado através de dois mecanismos: análises realizadas na fase do desenho do projeto que prevêem os riscos (e possíveis desvios à matriz); e ajustes periódicos da matriz, que ocorrem através de monitoramento a cada 12 meses. No entanto, para aqueles que implementam os projetos, 12 meses é um lapso de tempo longo demais para realizar tal ajuste, pois no dia a dia o projeto se depara com muitos imprevistos aos quais é preciso reagir para que possa seguir em frente.

Compreende-se assim a centralidade conferida pelos grupos da Tarrafa à chamada avaliação semanal da equipe, em que o planejamento inicial é ajustado à medida que imprevistos surgem (classificados como “dificuldades”, pois desviantes da matriz do projeto). Roberta, uma educadora do Galpão, explicou a importância da frequência de tais reuniões do seguinte modo: "É para não acumular.” O que acumula é justamente o descompasso entre a composição estabelecida pela matriz (que se cumpre como previsto apenas no vácuo social) e aquelas impressas pelo mundo dos beneficiários.

Com efeito, o dia a dia do trabalho com os meninos está sujeito a muitas eventualidades, como demonstra a fala de uma outra educadora do Galpão, Margareth, sobre a dinâmica na sua oficina:

Às vezes o tema nós mesmos trazemos, que são temas que a gente bota no planejamento anual e mensal de atividades do Galpão, mas também tem hora que os meninos trazem o tema que está mexendo muito com eles. Daí a gente tem que dar uma paradinha naquele tema que a gente estava trabalhando para dar mais atenção ao que eles estão gritando, alarmando, porque a gente não pode dar as costas para uma realidade que eles estão trazendo. Acho que o processo anda melhor dessa forma.

Se os meninos trazem algo que é mais alarmante, mais central para eles do que o tema planejado, este tem de ficar de lado, embora apenas temporariamente, já que o "mundo dos projetos”, o território da engenharia social, 
força a atenção e o retorno sucessivo à matriz de planejamento. Isso porque o mundo da vida opera um descompasso entre a composição duradoura, fixa (a matriz), e aquelas composições efêmeras, maleáveis, que se reconfiguram a cada vez que são atualizadas pelos atores à medida que estes reagem às contingências. Quanto mais as contingências afastam as atividades do planejamento inicial, ou seja, quanto mais composições efêmeras se deslocam da composição rígida, fixa, menos a matriz é boa medida de sucesso. Quanto mais contingências emergem e mudam o rumo das atividades, mais o projeto ruma ao fracasso apenas e tão somente por se afastar do planejamento inicial. O fracasso ou sucesso não é, evidentemente, estabelecido por alguma medida absoluta, mas pelo próprio desenho do projeto, e portanto sucesso significa o desenho do projeto evitar imprevistos ou prever riscos com acuidade, ou seja, que ele se dê na prática da forma mais similar possível a si mesmo.

Numa das reuniões semanais da equipe do Grupo Comunidade, quando foi anunciada a chegada da carta de aprovação do Projeto Tarrafa para o triênio 2006-2008, Liedson, um dos educadores, propôs que na reunião seguinte fosse distribuída "uma cópia do Projeto Tarrafa para cada educador colocar as coisas da proposta nas oficinas, porque tem muita coisa no projeto que precisa ser feita”. As reuniões semanais e os relatórios mensais dos educadores garantiriam o ajuste ao planejado. Como o eixo daquele ano era meio ambiente, Liedson sugeriu que fossem trabalhadas durante o mês de março atividades que explorassem a semana da água. Dona Valentina, uma das educadoras mais antigas, respondeu: "Não, agora é enfeite de Páscoa... faltam quatro semanas para a Páscoa.” De um lado, via-se um educador mais jovem preocupado em seguir o tema-eixo e adequar as atividades à matriz de planejamento para que o projeto se desse da forma mais similar possível a si mesmo. De outro lado, percebia-se uma educadora que dava mais importância a uma temporalidade que também perpassava o grupo, distinta daquela instaurada pela sucessão de eventos suposta na matriz.

Dona Valentina evidentemente não se identificava com a matriz, mas tampouco muitos dos funcionários da CAFOD. Isso ocorria não simplesmente, como creem os engenheiros sociais, pela pouca familiaridade com ferramentas de aplicação do procedimento lógico à solução de problemas, mas sobretudo pela temporalidade subjacente ao trabalho de engenharia social. Sob o ponto de vista de qualquer organização, seja uma agência financiadora com 400 funcionários, seja uma organização de base, quanto mais os emaranhados 
institucionais estiverem adensados em torno de si, mais as suas ações serão guiadas pelos princípios da engenharia social, o que implica a tentativa de excluir ao máximo outras temporalidades que eventualmente perpassam a organização, e a aproximação a uma forma de pensar que precisa supor o vácuo social para ser bem-sucedida.

\section{Referências}

BARROSO HOFFMAN, M. Fronteiras étnicas, fronteiras de Estado e imaginação da nação: um estudo sobre a cooperação internacional norueguesa junto aos povos indígenas. Rio de Janeiro: E-papers: Museu Nacional, 2009.

BOND. Logical framework analysis. guidance notes n. 4. London, 2003.

CAFOD. CAFOD 2010: building communities for change. London, 2005.

CAFOD. PCM handbook. London, Oct. 2007.

CASTRO, J. P. M. A invenção da juventude violenta: análise da elaboração de uma política pública. Rio de Janeiro: E-papers: Laced/Museu Nacional, 2009.

HARPER, R. The social organization of the IMF's mission work. An examination of international auditing. In: STRATHERN, M. (Ed.). Audit cultures: anthropological studies in accountability, ethics and the academy. London: Routledge, 2000. p. 21-54.

HERZFELD, M. Anthropology: theoretical practice in culture and society. Oxford: Blackwell Publishers, 2001.

HULL, M. Documents and bureaucracy. Annual Review of Anthropology, n. 41, p. 251-267, 2012.

LÉVI-STRAUSS, C. O pensamento selvagem. São Paulo: Editora Nacional, 1976.

MORAWSKA VIANNA, C. Os enleios da tarrafa: etnografia de uma parceria transnacional entre ONGs através de emaranhados institucionais de combate à pobreza. Tese (Doutorado em Antropologia Social)-Faculdade de Filosofia, Letras e Ciências Humanas, Universidade de São Paulo, São Paulo, 2010. 
NICAISE, N. C. M. A construção européia e os países em desenvolvimento: políticas de comunicação, generosidade, identidades. Tese (Doutorado em Antropologia Social)-Museu Nacional/Universidade Federal do Rio de Janeiro, Rio de Janeiro, 2007.

NORAD. The logical framework approach: handbook for objective oriented planning (LFA). Oslo, 1999.

ONG, A.; COLLIER, S. (Ed.). Global assemblages: technology, politics, and ethics as anthropological problems. Malden: Blackwell. 2005.

RIBEIRO, G. L. Transnational capitalism and hydropolitics in Argentina. Gainesville: University of Florida Press, 1994.

RIBEIRO, G. L. Poder, redes e ideologia no campo do desenvolvimento. Novos Estudos CEBRAP, v. 80, p. 109-125, 2008.

RICKLI, J. Negotiating otherness in the Dutch protestan world: missionary and diaconal encounters between the Protestant Church in the Netherlands and Brazilian organisations. Tese (Doutorado em Antropologia)-Departamento de Antropologia Social e Cultural, Vrije Universiteit Amsterdam, Amsterdam, 2010.

RILES, A. The network inside out. Ann Arbor: University of Michigan Press, 2001.

RILES, A. (Ed.). Documents: artifacts of modern knowledge. Ann Arbor: University of Michigan Press, 2006.

SCHRÖDER, P. A antropologia do desenvolvimento: é possível falar de uma subdisciplina verdadeira? Revista de Antropologia, São Paulo: USP, v.. 40, n. 2, p. 83-100, 1997.

SCHRÖDER, P.; NAASE, K. M. (Org.). Antropologia do desenvolvimento. Revista Anthropológicas, ano 8, v. 15, n. 2, 2004.

SILVA, K. C. da. A cooperação internacional como dádiva. Mana, Rio de Janeiro, v. 14, n. 1, p. 141-171, 2008. 
SILVA, K. C. da; SIMIÃO, D. S (Org.). Timor-Leste por trás do palco: cooperação internacional e a dialética da construção do Estado. Belo Horizonte: Editora UFMG, 2007.

STRATHERN, M. (Ed.). Audit cultures: anthropological studies in accountability, ethics and the academy. London: Routledge, 2000.

VALENTE, R. C. A GTZ no Brasil: uma etnografia da cooperação alemã para o desenvolvimento. Rio de Janeiro: E-papers: Laced/UFRJ, 2010. 